\title{
VIOLÊNCIA DOMÉSTICA: EVOLUÇÃO HISTÓRICA E ASPECTOS PROCESSUAIS NO ÂMIBITO DA LEI 11.340/2006
}

\author{
ANA KARINY L. PONTES \\ JULIANA DEAZEVEDO NERI
}

Alunas do curso de Direito da FA7, orientadas pelo prof. Rafael Gonçalves Mota.

julianaaneri@yahoo.com.br

Sumário: 1. Introdução; 2. A evolução da situação jurídica da mulher; 3 . As raízes internas de subordinação feminina; 4. Lei 11.340/2006: um avanço à proteção da mulher; 5. Análise processual dos dispositivos à luz da legislação existente; 6 . Avanços; 7. Conclusão.

Resumo: A Lei 11.340/06 aborda a aplicação de medidas mais rigorosas aos crimes praticados com violência doméstica e familiar. Trouxe inúmeras controvérsias no seu texto legal, modificando aspectos de direito material e processual penal. Desenvolvida com base no caso concreto de violência doméstica da Senhora Maria da Penha, como foi chamada a referida Lei. Destaque para a necessária e válida proteção aos direitos da mulher, mitigados desde a antiguidade. Avanços quanto a previsão de Juizados de Violência Doméstica e Familiar contra a mulher, afastando a aplicação da Lei 9.099/ 95, possibilitando a prisão em flagrante do agressor, não permitindo a aplicação de penas pecuniárias e a imposição de pagamento de cesta básica. Assegura a efetividade das medidas protetivas de urgência e a instauração de inquérito policial. Sua constitucionalidade é discutida, porém representa um eficaz instrumento para coibir a violência doméstica.

Palavras-chave: Direitos da Mulher. Lei 11.340/2006. Violência doméstica. Inconstitucionalidade. Avanços.

\section{INTRODUÇÃo}

A Lei 11.340 de 7 de agosto de 2006, também chamada de Lei Maria da Penha, pode ser considerada uma grande conquista tendo em vista as antigas limitações quanto aos direitos das mulheres. 
Proveniente de um caso concreto, abordado neste trabalho, procuramos através do método de pesquisa documental, trazer de forma clara o que se pode entender e interpretar diante da promulgação da referida Lei, que apesar de sofrer controvérsias em sua interpretação, pode ser vista por um olhar positivo, visto que, a mesma prevê em seus artigos várias medidas protetivas, como a garantia de proteção policial, a obrigação imposta ao ofensor de afastar-se do lar, bem como o encaminhamento da ofendida e seus dependentes a programas oficiais de atendimento, entre outras, deferidas em caráter de urgência que tem como objetivo fazer cessar a violência que atormenta a vida de inúmeras mulheres não só brasileiras, sendo tal estatística cada vez mais alarmante, fazendo-se necessário a tomada de atitudes por parte do Poder Público.

O trabalho tem como base vários temas, como a evolução dos direitos femininos, a partir dos tempos primitivos até os dias atuais, posteriormente foi feito um estudo mais subjetivo das causas e conseqüências da violência doméstica, partindo para uma análise da Lei 11.340/06, em seus diversos âmbitos, com destaque para o caráter processual penal, englobando os avanços trazidos pela mesma, bem como, a necessidade dos Juizados Especiais, as críticas e as inconstitucionalidades discutidas a partir da interpretação de seus dispositivos.

Por fim, a pesquisa foi feita através da análise minuciosa da Lei, dos trabalhos e obras publicados sobre o tema, embora de difícil compilação devido ao pequeno número de fontes disponibilizadas, por ser o assunto ainda pouco desenvolvido no contexto jurídico.

\section{T2 A EVOLUÇÃO DA SITUAÇÃo JURÍDICA DA MULHER}

Primitivamente a mulher exercia uma função social igual a do homem, enquanto este ia caçar e pescar a mulher desempenhava as atividades agrícolas e as tarefas domésticas, sendo as comunidades primitivas desprovidas de matérias jurídicas, prevalecendo o direito repressivo (Tabosa, 2005).

Com a evolução da sociedade e sua complexidade, o direito como efeito das mudanças também evoluiu, porém em relação a mulher o desenvolvimento se dá muito lentamente, visto que com o aumento da riqueza individual do homem, a monopolização política e a queda do direito materno ocorreu uma enorme desigualdade jurídico-social, entre homens e mulheres, visto desde o Direito Romano, que desprovia a mulher de capacidade jurídica, com exemplo de que a mulher solteira, vivia sob o pátrio poder do pai e se casada vivia sob o poder do marido (Tabosa, 2003).

No Brasil-Colônia permaneceu a diferenciação quanto a educação feminina, em que a igreja agora dominante deu início a educação não incluindo as mulheres, tendo estas dois motivos para viver, quais sejam, o lar e a igreja, submissas ao pai, ao marido e a religião. Esta submissão se dava ao fato do desejo de mantê-las alienadas quanto aos conhecimentos que lhes permitissem pensar em igualdade de direitos, não permitindo a elas, estudar e aprender. 
Ao homem não era imputado pena quanto a aplicação de castigos corporais à mulher e aos filhos, o pátrio poder era de exclusividade do marido, não podendo a mulher, praticar quase nenhum ato sem autorização do mesmo, sendo este o período das Ordenações Filipinas que vigeu por mais de trezentos anos, até o ano de 1916.

Com a implantação do regime republicano brasileiro, foi mantido o poder patriarcal, porém de forma mais branda, tendo sido retirado do marido o direito de impor castigos corporais a mulher e aos filhos.

A promulgação do Código Civil de 1916 manteve os princípios conservadores do homem como chefe da sociedade conjugal, deixando sem dúvida a nítida colocação da mulher em segundo plano.

Com o Código Eleitoral em 1932, surgiram avanços, ao ser permitido o voto feminino às mulheres maiores de 21 anos, que após a constituição de 1934 foi reduzida a idade exigida para 18 anos.

Diante da situação de inferioridade da mulher, há quem diga que a mesma decorre da constituição física do sexo feminino, o que hoje se tem conhecimento de não ser essa teoria de todo verdade, bem como há quem afirme ser essa subordinação, sustentada durante tanto tempo, conseqüência do surgimento da propriedade privada e o destaque do homem nas negociações mercantis e capitalistas, dando a ele os meios de produção e colocando a mulher em situação econômica desfavorável.

Porém, a partir do momento que a mulher passou a produzir riquezas, em um mundo hoje capitalista, passou a auferir espaço no mercado de trabalho com sua contribuição econômica, selando, portanto, sua independência, surgindo o equilíbrio entre os direitos e obrigações dos homens e das mulheres, principalmente a partir da Lei 4.121/ 62, que teve como mérito abolir a incapacidade feminina, revogando normas discriminadoras constantes no Código Civil de 1916, consagrando o princípio do livre exercício de profissão da mulher casada, com a possibilidade do seu ingresso livremente no mercado de trabalho, trazendo significativas mudanças no relacionamento dos cônjuges.

A igualdade dos sexos, também foi abordado a partir da Constituição de 1824, passando a ter maior destaque com o advento da Constituição de 1967, que afirmou a igualdade jurídica entre homens e mulheres em seu art.153, in verbis: "Todos são iguais perante a lei, sem distinção de sexo, raça, trabalho e credo religioso e convicções políticas políticos. O preconceito de raça será punido pela lei”. Prevendo, portanto, penalidades em face do preconceito.

\section{B. AS RAÍZES INTERNAS DE SUBORDINAÇÃO FEMININA}

Desde a antiguidade, a mulher é vítima de discriminação, sendo esta tratada como um objeto, como mencionado acima, tendo seus direitos limitados e suas vontades e liberdades tolhidas, resultados de uma discriminação sócio-cultural envolta ao machismo exacerbado, havendo uma dominação dos homens que de alguma forma ocupam patamares mais elevados, econômica e politicamente, bem como perante a família, criando assim pólos de dominação e submissão. 
Diante dessa suposta superioridade masculina está vigente um grave problema, denominado de violência doméstica, que atinge cerca de $25 \%$ (vinte e cinco por cento) a 50\% (cinqüenta por cento) das mulheres na América Latina, que perfazem uma estimativa de cerca de quatro mulheres por minuto no Brasil, vítimas de tal violência, contando com dois milhões de casos por ano, tendo este tipo penal já sido vivenciado por uma em cada cinco mulheres no Brasil, conforme pesquisa realizada pela Fundação Perseu Abramo, em 2001 (Viana, 2007, p. 13-18).

Porém, o que se observa é que as mulheres vítimas de violência se sentem intimidadas a denunciarem seu companheiro, marido, namorado, ex-cônjuge, pai, dentre outros, seja por fatores internos de subordinação, como a esperança de que não mais irá se repetir o fato, com a promessa de manter o relacionamento, ou por sentir-se culpada pela violência, ou até mesmo por dependência financeira, vergonha ou medo de sofrerem novas agressões, tomando assim uma posição de submissão, favorecendo a impunidade do agressor.

A situação de violência doméstica é composta por um ciclo gradativo, e pode ser de diversas formas, como define a Lei 11.340/06 em seu art. $7^{\circ}$, visto que a mesma não se caracteriza somente pela agressão física, mas também pela violência psicológica que visa causar dano emocional e diminuição da auto-estima da mulher, prejudicando e perturbando seu pleno desenvolvimento, por meio de humilhações, manipulação, isolamento, entre outros, bem como, pode haver a violência sexual, em que seja a mulher constrangida a presenciar, manter ou participar de relação sexual não desejada ou ser ela induzida a comercializar ou a utilizar, de qualquer modo sua sexualidade. Por fim pode a violência contra a mulher ser de ordem patrimonial e moral, sendo aquela caracterizada pela conduta que configure retenção, subtração, destruição parcial ou total de objetos pertencentes à mulher, e esta érepresentada por condutas que configure calúnia, difamação ou injúria. No entanto, o que se percebe é que, não havendo conseqüências graves, o que ocorre em muitos dos casos é a fase de conciliação, com o pedido de perdão pelo agressor, geralmente aceito pela agredida que dá margem para que tal fato se repita.

\section{LEI 11.340/2006: UM AVANÇO À PROTEÇÃO DA MULHER}

Um caso concreto de violência doméstica ensejou na promulgação da Lei 11.340/ 06, conhecida como Lei Maria da Penha, uma vitoriosa conquista em benefício da proteção da mulher contra a violência doméstica, inserida no âmbito legislativo por iniciativa da sra. Maria da Penha Maia Fernandes, cearense, farmacêutica, que no dia 29 de maio do ano de 1983, sofreu uma tentativa de homicídio quando dormia, tendo sido atingida por um tiro de espingarda, disparado por seu marido, Marco Antônio Heredia Viveiros, colombiano de origem, naturalizado brasileiro que mesmo alegando serem os fatos decorrentes de um assalto, ficou provado, posteriormente, a inveracidade das alegações, com a conseqüente confirmação de sua autoria no crime. Em razão desse tiro a vítima sofreu lesões que a deixaram paraplégica, por ter atingido a terceira e quarta vértebra de sua coluna. 
Porém as agressões não cessaram, tendo o mesmo tentado matá-la, pela segunda vez, com uma corrente elétrica quando a vítima encontrava-se no banho, atos, por sua vez, marcados por premeditações, visto que por várias vezes o senhor Antônio tentou convencer a esposa a celebrar um seguro de vida, sendo ele o beneficiário.

No dia 28 de setembro de 1984, o Ministério Público denunciou o agressor perante a $1{ }^{\text {a }}$ Vara Criminal de Fortaleza, em que foi o réu pronunciado em 31 de outubro de 1986 e levado ao Tribunal do Júri em 4 de maio de 1991, quando foi condenado. O recurso da defesa foi acolhido, com alegações de falha na elaboração dos quesitos; assim, o réu foi submetido a um novo julgamento, no dia 15 de março de 1996, sendo condenado a dez anos e seis meses de prisão, do qual novamente ele apelou e ingressou com recursos aos Tribunais, restando finalmente preso, em setembro de 2002, portanto 19 anos depois da ocorrência do fato (Cunha e Pinto, 2007, p. 11-16).

Foi com a luta por justiça e a persistência da vítima deste caso, no sentido de conseguir a efetiva punição de seu agressor que surgiu a Lei 11.340/06, trazendo inúmeras inovações no que concerne ao procedimento que o Judiciário anteriormente utilizava para resolver os casos de violência doméstica.

Para entender melhor a vitória alcançada por esta Senhora e por toda a sociedade com o advento da nova Lei, faz-se necessário perpassar por todo o histórico da violência doméstica na legislação pátria.

Inicialmente, a legislação não trazia um dispositivo que tratasse especificamente sobre agressões praticadas no ambiente familiar e doméstico, sendo estas enquadradas no tipo penal lesão corporal leve (CP, Artigo 129, caput).

Após longos anos, onde ocorreram inúmeros movimentos em prol da garantia dos direitos humanos, que continuavam a ser violados, surgiu a Lei 10.886/04, que acrescentou o $\S 9^{\circ}$ ao Artigo 129 do Código Penal, passando a existir, dispositivo específico a respeito do tipo penal violência doméstica contra ascendente, descendente, irmão, cônjuge ou companheiro, ou com quem conviva ou tenha convivido.

Diante dessa mudança, a pena mínima aumentou de 3 meses para 6 meses, mas a pena máxima continuou a mesma, 1 ano. O crime permaneceu sendo de menor potencial ofensivo, regido, portanto, nos conformes da Lei 9.099/95, cabendo a suspensão condicional do processo (art. 89), transação penal (art. 76) e a aplicação de penas restritivas de direitos, em detrimento da pena privativa de liberdade (art. 44).

A acanhada iniciativa não proporcionou a solução desejada para combater a violência doméstica dentro da família, principalmente contra as mulheres, tendo em vista que os agressores não se amedrontavam com as possíveis conseqüências de suas atitudes, pois sabiam que sempre seriam penalizados com medidas alternativas, além da certeza de que não seriam presos em flagrante delito, caso se comprometessem a comparecer ao Juizado Especial Criminal, onde seria elaborado um termo circunstancial.

Enfim, com muito empenho na tentativa de coibir a violência doméstica e familiar contra a mulher, tendo em vista que esta é a maior vítima deste crime, entrou em vigor em 21/set/2006 a lei federal 11.340, que alterou o Código de Processo Penal, o Código 
Penal e a Lei de Execução Penal, tendo como objetivo satisfazer as expectativas das entidades de defesa dos direitos das mulheres e cumprir o disposto no $\S 8^{\circ}$ do art. 226 da Constituição Federal, assim como o que objetivam a Convenção sobre eliminação de todas as formas de discriminação contra as mulheres e a Convenção Interamericana para prevenir, punir e erradicar a violência contra a mulher.

\section{F-Análise processual dos dispositivos à LUZ Da LEGISLAÇÃO EXISTENTE}

A Lei Maria da Penha, como assim ficou conhecida, trouxe uma série de controvérsias em relação à legislação já existente, causando embaraço ao aplicador do direito no momento da interpretação dos seus dispositivos.

O artigo 16 da referida Lei ocasiona de imediato uma confusão no que concerne ao emprego dos termos jurídicos, renúncia e retratação, posto que aquela nos remete a hipótese de desistência da vítima de propor a ação penal privada, não sendo prevista, em geral, para as ações públicas, enquanto a retratação é, no processo penal e no direito penal, a desistência da manifestação da vontade da vítima de dar prosseguimento à fase do inquérito policial ou de oferecer a denúncia nas ações públicas. É perceptível o embaraço que o legislador ocasionou, quando ao referir-se à renúncia, objetivou na verdade trazer o instituto da retratação à representação, que pode ser utilizado pela vítima antes do recebimento da denúncia ${ }^{1}$.

Urge salientar, que ainda no mesmo liame, há quem apresente interpretação de que nem sequer pode-se igualmente mencionar a hipótese de retratação, visto que depois de oferecida a denúncia, ex officio pelo Ministério Público, é que a vítima precisa comparecer em audiência, momento em que poderá exercitar seu direito de representação ainda não manifesto, pois estes defendem que até a ocasião só quem agiu foi a autoridade policial e o Ministério Público, independente da manifestação de vontade da vítima ${ }^{2}$.

No entanto, discordamos desse posicionamento, em razão de entendermos que a vítima oferece sua representação mesmo tacitamente, quando comparece perante a autoridade policial para denunciar o agressor, cabendo, portanto, perfeitamente o instituto da retratação da representação, em audiência procedida para tal finalidade, nos casos de ação pública condicionada.

${ }^{1}$ COSTA JR., Quintino Farias. Ação Penal Pública Condicionada e a Lei Maria da Penha: algumas considerações.

Disponível em: <http://www.mp.pa.gov.br/caocriminal/arquivos/acao_penal_publica.pdf > Acesso em: 15 maio 2007.

2 CABETTE, Eduardo Luiz Santos. Anotações críticas sobre a lei de violência doméstica e familiar contra a mulher. Disponível em: $<$ http://jus2.uol.com.br/doutrina/texto.asp?id=8822 $>$. Acesso em: 15 maio 2007. 


\subsection{AÇÃO PÚBLICA CONDICIONADA À REPRESENTAÇÃOO OU INCONDICIONADA}

No diapasão do tipo de ação que cabe quando se trata da Lei Maria da Penha, surge um embaraço para o aplicador do direito, em razão da possibilidade de ser entendido tanto como crime de ação pública incondicionada como de ação pública condicionada à representação, dependendo da interpretação adotada.

A primeira afirma que a exclusão da aplicação da Lei 9.099/95, portanto, também do seu artigo 88, que prevê a representação como condição de procedibilidade, dá margem à conclusão de que não é mais possível a representação da vítima, passando a ação a ser pública incondicionada (Jesus, 2006, p.46).

Outros apresentam interpretação no sentido de que embora o artigo 16 da Lei 11.340/06, trate da representação, presente na ação penal pública condicionada, a autoridade policial tomando ciência da notitia criminis deverá agir de ofício, independente da manifestação da vítima, como ocorre nas ações públicas incondicionadas ${ }^{3}$.

Em oposição aos entendimentos supracitados, existem correntes que defendem que o crime é de ação pública condicionada, por diversas razões.

A primeira razão para o crime ser interpretado como de ação pública condicionada à representação, consiste na idéia de que o legislador ordinário deixou transparente no artigo 16 da Lei que será cabível retratação da representação nas ações penais públicas condicionadas de que trata o texto legal, não havendo, portanto, o que discutir acerca da questão. Ainda assim, acreditam que a intenção do legislador infraconstitucional, ao retirar da apreciação dos Juizados Especiais Criminais os crimes que envolvem violência doméstica contra a mulher, não foi a de derrogar ou revogar o artigo 88 da Lei 9.099/ 95 , o que levaria a conclusão de que o crime deixou de ser de ação pública condicionada para ser incondicionada, mas sim de proibir a aplicação de todos os benefícios que esta Lei traz quanto a aplicação da pena ao agressor (Jesus, 2006, p. 46).

A nossa posição acerca desta situação consiste em defender que não há um tipo específico de ação penal pública trazido no texto legal. A razão é bastante simples. O legislador infraconstitucional ao elaborar a Lei Maria da Penha não tipificou nenhum crime, apenas trouxe uma série de medidas e mudanças a serem aplicadas aos tipos penais já existentes, quando estes fossem cometidos no contexto da violência familiar e doméstica. Assim, a natureza da ação penal continua a ser determinada pelo Código Penal, a ser definido de acordo com a gravidade do crime cometido, salientando-se que existem inúmeros crimes que podem encaixar-se na aplicação das inovações trazidas pela Lei 11.340/06.

${ }^{3}$ CABETTE. 


\subsection{LAPSO DE TEMPO ENTRE O OFERECIMENTO E O RECEBIMENTO DA DENÚNCIA}

O texto em comento traz outra dúvida acerca de suas pretensões no momento em que deixa um lapso de tempo entre o oferecimento da denúncia pelo Ministério Público, através da manifestação da vontade tácita da vítima que vai até a delegacia denunciar o agressor, e o seu recebimento pelo magistrado, admitindo, assim, que haja a retratação da representação e, conseqüentemente, o impedimento da continuidade da persecução criminal. Ocorre que, o Código de Processo Penal Brasileiro é cristalino quanto a irretratabilidade da representação após o oferecimento da denúncia, como assim dispõe o seu artigo 25, portanto, de acordo com este dispositivo, quando é oferecida a denúncia será esta de imediato recebida pelo magistrado, o que induz a conclusão de que não se faz distinção entre o seu oferecimento e o recebimento, diferente do que está disposto na Lei Maria da Penha, que inclusive acarreta o desrespeito ao princípio da indisponibilidade do órgão ministerial depois de iniciada a sua atuação na ação penal, pois existe a possibilidade da desistência da vítima, após iniciada a atuação do promotor de justiça ${ }^{4}$.

Importante salientar a razão para a existência de tal audiência que possibilita a retratação da vítima quanto à representação, pois é nesta que estarão presentes o promotor de justiça, as partes e o juiz, possibilitando que a vítima possa continuar imperiosa no interesse em processar o agressor ou desistir, de tal maneira que poderá ocorrer duas situações durante a audiência: 1 - a vítima não se retratar, momento em que a denúncia será recebida pelo Juiz; 2 - haver reconciliação entre as partes em litígio, e conseqüentemente a retratação da vítima e o arquivamento do inquérito policial; 3 - o Ministério Público ingressar com a denúncia perante o magistrado, quando aquele atua como dominus litis (domínio da lide), sendo competente para exercer tal função; 4 - o próprio magistrado concluir durante a audiência que deve haver a denúncia, mesmo havendo a retratação da vítima, hipótese em que se o promotor de justiça não oferecer a denúncia, o juiz enviará os autos à Procuradoria Geral de Justiça, em analogia ao artigo 28 do Código de Processo Penal, onde será decidido pelo procurador geral se deve haver ou não a denúncia.

Todas as medidas supracitadas dependerão da natureza da ação penal apropriada ao crime cometido. Para esclarecer melhor podemos citar como exemplo o crime de homicídio praticado no âmbito familiar ou doméstico, o que enseja ação penal pública incondicionada, podendo o Ministério Público agir independente da vontade da parte, devido ao interesse público na causa em questão. De outro ângulo, sendo um crime de ação pública condicionada à representação, a denúncia dependerá da vontade da parte.

${ }^{4}$ COSTA JR. 


\subsection{JUIZADOS ESPECIAIS}

Os casos que envolviam violência doméstica, quando inclusos no tipo penal lesão corporal leve, antes da Lei 9.099/95 eram encaminhados para a Justiça Comum Criminal, competente para julgar tais casos.

Em 1995, com o advento da supramencionada Lei, todos os crimes com pena máxima de até 1 ano, nos moldes do seu artigo 61, passaram a ser da competência dos Juizados Especiais Criminais.

Com a implementação do $\S 9^{\circ}$ ao Artigo 129 do CP, através da Lei 10.886 de 2004, a pena máxima do crime de violência doméstica foi fixada em 1 ano, ou seja, a mesma do crime descrito no caput do artigo, permanecendo competentes os Juizados Especiais. As duasúnicas diferenças foram quanto a pena mínima que aumentou, e em relação à natureza da ação penal, que passou a ser incondicionada, diferente do caput, em que a ação é condicionada à representação, nos moldes do artigo 88 da Lei 9.099/95.

Percebe-se que embora o tema tenha sido tipificado de forma específica, havendo avanços na legislação quanto a abordagem da violência doméstica, continuou ela por muito tempo sem conseguir ter a efetividade esperada por uma sociedade que ansiava por medidas que diminuíssem a incidência do crime.

Somente com a Lei 11.340/06 alcançou-se efetivamente uma grande vitória, principalmente para os movimentos feministas de defesa dos direitos das mulheres, pois agora o crime de violência doméstica passou a ser de competência dos Juizados de Violência Doméstica e Familiar contra a mulher, estes ainda não existentes, mas que devem ser criados especialmente para atender esse tipo de demanda, que por enquanto serão da competência das Varas Criminais, enão mais dos Juizados Especiais Criminais, tendo em vista que a Lei Maria da Penha, de acordo com o art. 41, é taxativa ao proibir a aplicação da Lei 9.099/95 nos crimes praticados com violência doméstica e familiar contra a mulher, independente da pena.

\subsection{Alterações do Código Penal, na Lei de Execução Penal e no Código de Processo Penal com a Lei Maria da Penha}

Inicialmente, no que concerne às circunstâncias agravantes da pena, dispostas no art. 61 do Código Penal, houve um acréscimo na parte final da alínea " f”, para abranger a violência contra a mulher.

Uma segunda mudança é encontrada no âmbito da pena aplicada às agressões domésticas, quando se tratar do crime tipificado no $\S 9^{\circ}$ do art. 129 do CP, que passou de 6 meses para 3 meses, enquanto a máxima passou de 1 ano para 3 anos, além de ser aumentada de um terço se o crime for cometido contra pessoa portadora de deficiência.

No que se refere à Lei de Execução Penal, ${ }^{0}$ 7.210/84, houve um acréscimo na sua redação para implementar o parágrafo único no artigo 152, que dispõe que o juiz poderá determinar o comparecimento obrigatório do agressor a programas de 
recuperação e reeducação, instituto que antes não era regulado pela referida Lei.

Finalmente, podemos mencionar a mudança do Código de Processo Penal, que também teve a norma do art. 313 ampliada, para abranger mais uma causa que permite a decretação da prisão preventiva, posto que acrescentou o inciso IV, in verbis: "se o crime envolver violência doméstica e familiar contra a mulher, nos termos da lei específica, para garantir a execução das medidas protetivas de urgência."

\subsection{Inconstitucionalidade da Lei Maria da Penha}

A Lei em um primeiro momento causa confusão quanto a sua constitucionalidade, no sentido de que alguns estudiosos argumentam que a norma somente aborda casos de violência doméstica contra a mulher, ferindo, assim, o princípio da isonomia garantido constitucionalmente para todos, ou seja, homens e mulheres, não podendo, então, existir uma lei que assegure apenas os direitos das mulheres, quando esses mesmos crimes podem ser cometidos também contra o sexo oposto.

O que não é admitido por estes doutrinadores, portanto, é que um homem violente seu pai ou seu filho, por exemplo, e seja processado e julgado nos moldes da Lei 9.099/95, sendo beneficiado com uma pena alternativa, multa ou suspensão condicional do processo, enquanto o mesmo crime quando é praticado contra a mulher não terá os mesmos privilégios, respondendo, o infrator, com medidas mais severas, nos moldes da Lei 11.340/06. Ainda assim, seguindo a mesma linha de raciocínio, quando a mulher comete a infração contra o seu marido, seu pai ou seu filho, responderá também nos moldes da Lei 9.099/95, ferindo novamente o princípio da igualdade, quando faz distinção, no procedimento e nas medidas judiciais adotados.

Somos do entendimento de que tal alegação de inconstitucionalidade é improcedente, tendo em vista que a intenção do legislador ao fazer uma Lei que busca a garantia dos direitos da mulher é exatamente a de colocar a mulher em pé de igualdade com o homem, tendo em vista que isso ainda não é uma questão bem estruturada e aceita em nossa sociedade conservadora, que tem a visão da mulher como um ser frágil e inseguro, que precisa estar submisso a um ser superior, o homem. É tão evidente o caráter da sociedade nesse aspecto, que é exatamente por isso que existe a muitos anos a luta de organizações da sociedade civil juntamente com organizações internacionais, buscando a efetivação da garantia dos direitos dessas mulheres, e não dos homens, que, em regra, não sofrem este tipo de discriminação. Além de tudo já exposto, ainda assim achamos impertinente a posição de alguns doutrinadores ao levantar a inconstitucionalidade da Lei Maria da Penha pela justificativa supracitada, uma vez que existem legislações que surgiram para proteger determinadas pessoas, que da mesma forma que as mulheres, possuem suas peculiaridades em relação às outras, $\mathrm{e}$ precisavam da efetivação de seus direitos, como é o exemplo dos idosos e das crianças e adolescentes, o que deu ensejo ao surgimento, respectivamente, do Estatuto do Idoso e do Estatuto da Criança e do Adolescente. 
Outro aspecto que desperta discussão a respeito da inconstitucionalidade da Lei Maria da Penha encontra-se no seu art. 33, que afasta a competência dos Juizados Especiais para receber demandas que tratem de violência doméstica contra a mulher, ou seja, o texto legal versa sobre matéria de organização judiciária, afastando a competência que é privativa do Poder Judiciário $\left(\mathrm{CF}, 125, \S 1^{\circ}\right)$, e assim, fere o princípio da separação dos poderes (Dias, 2007. p. 58-59).

Sobretudo, não há inconstitucionalidade devido a definição de competência, uma vez que além do legislador infraconstitucional não ter ultrapassado seus limites, não é a primeira vez que isso ocorre, tendo como exemplo o afastamento da Lei 9.099/95 do âmbito dos crimes militares.

\section{(i) Avanços}

As contribuições trazidas pela lei com diversos benefícios em prol das mulheres foram de significativa importância. De imediato podemos citar a inovação que a Lei aborda quanto a criação de Juizados de Violência Doméstica e Familiar contra a Mulher, que terão a finalidade de cuidar de todas as causas que envolvem violência doméstica, abrangendo os aspectos penais e extrapenais. Urge salientar, que diante da realidade brasileira, é evidente que os Juizados Especializados não serão criados imediatamente, o que transfere, durante esse período, a competência, civil e criminal, para as Varas Criminais.

$\mathrm{O}$ texto legal não se limita a esta inovação. $\mathrm{O}$ art. 12 prevê a mudança no procedimento utilizado quando a mulher chega até a delegacia para denunciar seu agressor, posto que não é mais lavrado TCO (Termo Circunstanciado de Ocorrência), que é apenas um registro de ocorrência que contém as informações da vítima, sendo feito agora um BO (Boletim de Ocorrência), onde os fatos serão melhor apurados, dando ensejo a instauração do inquérito policial. Essa mudança substancial foi salutar para as vítimas, uma vez que anteriormente, querendo a agredida deixar imediatamente de conviver sob o mesmo teto do agressor, teria que ingressar com uma ação cautelar de separação de corpos, que na grande maioria das vezes era indeferida pelo juiz, tendo em vista que estes consideravam o TCO uma prova unilateral, portanto, de pouco valor probatório. Agora, com a utilização do BO e, então, uma melhor apuração dos fatos, além da garantia trazida pela Lei de aplicação de medidas protetivas de urgência, poderá a autoridade policial, a requerimento da ofendida, encaminhar o pedido ao juiz competente, no prazo de 48 horas, para que sejam tomadas as medidas cabíveis. Ressalta-se, que a vítima passa a estar sempre acompanhada de advogado, tanto na fase policial como na judicial, sendo assistida pela Defensoria Pública quando não possuir condições financeiras.

Foram implantadas medidas protetivas, de caráter extrapenal, que proporcionam a mulher uma maior segurança para denunciar os agressores, uma vez que elas podem pedir a concessão das medidas de urgência, o que as deixam mais confiantes na hora de denunciar, tendo em vista que serão amparadas pelo Estado. 
Na mesma esteira, certamente progrediu-se com a restauração da possibilidade da prisão em flagrante, que era inviável no período em que se aplicava a Lei 9.099/95 nos casos de violência doméstica, devido a redação do seu art. 69, que afastava a prisão em flagrante quando o agressor, nos crimes de menor potencial ofensivo, se comprometia a comparecer espontaneamente aos Juizados Especiais Criminais. Com a alteração, o agressor fica mais inibido quando cogita cometer o crime. Outrossim, houve um acréscimo feito ao inc. IV do art. 313 do CPP, com a criação de outra possibilidade de prisão preventiva, não mais restrita aos crimes punidos com reclusão, o que transmite às mulheres brasileiras menos insegurança diante das conseqüências que sua denúncia possa gerar.

Finalmente, aponta-se uma novidade trazida pela Lei 11.340/06 que, preocupa-se com a estabilidade no emprego da mulher agredida, nos moldes do art. $9^{\circ} \S 2^{\circ}$, in verbis:
Art. 9o Aassistência àmulher em situação de violência doméstica e familiar será prestada de forma articulada e conforme os princípios e as diretrizes previstos na Lei Orgânica da Assistência Social, no Sistema Único de Saúde, no Sistema Único de Segurança Pública, entre outras normas e políticas públicas de proteção, e emergencialmente quando for o caso.
[...]
$\S 2^{\circ}$ O juiz assegurará à mulher em situação de violência doméstica $\mathrm{e}$ familiar, para preservar sua integridade física e psicológica:
I - acesso prioritário à remoção quando servidora pública, integrante da administração direta ou indireta;
II - manutenção do vínculo trabalhista, quando necessário o afastamento do local de trabalho, por até seis meses."

Tal disposição legal é muito criticada por doutrinadores, no aspecto de que embora a lei tenha sido sábia na abordagem do instituto, não definiu quem seria responsável pelo pagamento de sua remuneração no respectivo período.

\section{ConCLUSÃo}

A Lei Maria da Penha surgiu apresentando diversos aspectos criticáveis, sob o ponto de vista técnico, ou seja, jurídico, criminológico e de política criminal, o que gerou um desafio aos operadores do Direito.

No entanto, a violência contra a mulher está a cada ano aumentando de forma absurda, o que ensejava, já tardiamente, a necessidade de algo que freasse e estancasse os índices até então alarmados. Foi exatamente com a perspectiva de mudar essa realidade que surgiu a Lei, que deve ser vista sem preconceitos e com o espírito desarmado por parte dos operadores do direito. 
Destarte, é necessário que deixem a Lei agir, para no futuro concluirmos se os objetivos foram ou não alcançados, chegando a um consenso a respeito da sua aplicabilidade prática, para que daí sejam tomadas as medidas necessárias para corrigir suas controvérsias e imperfeições.

Enfim, inegavelmente, a intenção do legislador foi muito boa, havendo uma grande conquista para a sociedade, que passa a adquirir um instrumento capaz de pressionar o Estado a aplicar as medidas protetivas e coercitivas mais severas em favor das mulheres agredidas no ambiente doméstico e familiar.

\section{Bibliografia}

BERARDI, Luciana Andréa Accorsi. Políticas afirmativas de gênero e o Direito Brasileiro. Disponível em: $<$ http://www.direitonet.com.br/artigos/x/21/23/2123/> Acesso em: 20 maio 2007.

BRASIL. Lei 9.071, de $1^{\circ}$ de janeiro de 1916.

BRASIL. Decreto n. 2848, de 7 de dezembro de 1940.

BRASIL. Decreto n. 3689, de 3 de outubro de 1941.

BRASIL. Lei 7.210, de 11 de julho de 1984.

BRASIL. Lei n. 9.099, de 26 de setembro de 1995.

BRASIL. Lei n. 10.886, de 17 de junho de 2004.

BRASIL. Lei n.11.340, de 7 de agosto de 2006.

BRASIL. Constituição (1988). Constituição da República Federativa do Brasil. Brasília: DF, Senado, 1988.

CABETTE, Eduardo Luiz Santos. Anotações críticas sobre a lei de violência doméstica e familiar contra a mulher. Disponível em: $<$ http://jus2.uol.com.br/ doutrina/texto.asp?id=8822>. Acesso em: 15 maio 2007.

CAPEZ, Fernando. Curso de Processo Penal. 14 ed. São Paulo: Saraiva, 2007.

CUNHA, Rogério Sanches e PINTO, Ronaldo Batista. Violência Doméstica (Lei Maria da Penha): Lei 11.340/2006. Comentada artigo por artigo. São Paulo: Revista dos Tribunais, 2007.

DIAS, Maria Berenice. A Lei Maria da Penha na Justiça: a efetividade da Lei 11.340/2006 de combate à violência doméstica e familiar contra a mulher. Rio de Janeiro: Revista dos Tribunais, 2007.

DIAS, Maria Berenice. Revista Brasileira de Ciências Criminais. fev. 2007. 
GOMES, Luiz Flávio e BIANCHINI, Alice. Lei de Violência contra a Mulher. Revista Consulex, Brasília, Ano X, n. 233, set. 2006.

JESUS, Damásio. Violência Doméstica e Familiar contra a mulher. Revista Consulex, Brasília, Ano X, n. 237, nov. 2006.

JESUS, Damásio. Violência Doméstica e Familiar contra a mulher. Revista Consulex, Brasília, Ano X, n. 237, nov. 2006.

COSTA JR., Quintino Farias. Ação Penal Pública Condicionada e a Lei Maria da Penha: algumas considerações. Disponível em: $<$ http://www.mp.pa.gov.br/caocriminal/ arquivos/acao_penal_publica.pdf $>$. Acesso em: 15 maio 2007.

MIRABETE, Júlio Frabbrini. Processo Penal. 17 ed. rev. e atual. São Paulo: Atlas, 2005.

MIRABETE, Júlio Fabbrini e FABBRINI, Renato N. Manual de Direito Penal, volume 2: Parte Especial, Arts. 121 a 234 do CP. 25. ed. rev. e atual. até 31 de dezembro de 2006. São Paulo: Atlas, 2007.

TABOSA, Agerson. Direito Romano. 2 ed., Fortaleza: FA7 - Faculdade 7 de Setembro, 2003.

TABOSA, Agerson. Sociologia Jurídica. Fortaleza: Qualygraf, 2005.

VIANA, Karoline e ANDRADE, Luciana. Crime e Castigo. Revista Jurídica Leis \& Letras. Ceará. n. 6, 2007.

\title{
DOMESTIC VIOLENCE: HISTORICAL EVOLUTION AND PROCESSUAL ASPECTS ACCORDING TO FEDERAL LAW N. 11.340/2006
}

\begin{abstract}
The federal law n. 11.340/06 applies more severe penalties in cases of domestic and familiar violence crimes. It brought several controversies in its legal text, altering aspects of criminal law. The law is named after Maria da Penha, a woman who inspired many, due to her case of domestic violence, practiced by her husband. Some legal aspects are pointed out: the necessary and valid protection of woman's rights; changes in the special courts regulations; impossibility of applying fines; assurance of urgent police reports. Although its constitutionality is questioned, the law is seen as an efficient tool against domestic violence.
\end{abstract}

Key words: Woman's rights. Federal law n. 11.340/2006. Domestic violence. Inconstitutionality. Progress. 